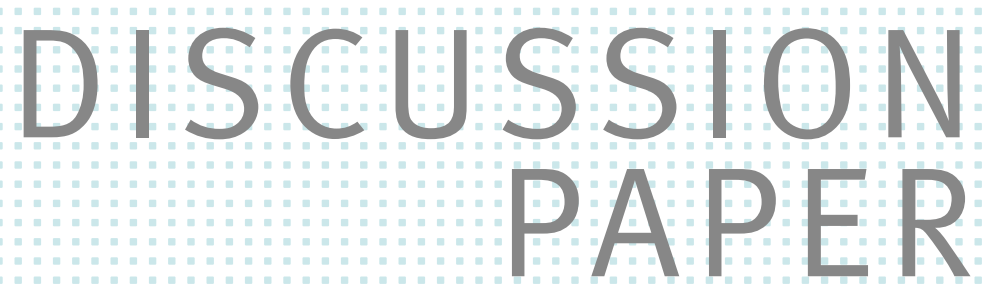

/ / VITALI GRETSCHKO AND MARTIN POLLRICH

\title{
Incomplete Contracts in Dynamic Procurement
}




\title{
INCOMPLETE CONTRACTS IN DYNAMIC PROCUREMENT
}

\author{
VITALI GRETSCHKO AND MARTIN POLLRICH
}

\begin{abstract}
We analyze the problem of a buyer who purchases a long-term project from one of several suppliers. A changing state of the world influences the costs of the suppliers. Complete contracts conditioning on all future realizations of the state are infeasible. We show that contractual incompleteness comes without a cost. The buyer achieves the same surplus with complete and incomplete contracts. The key insight is that the allocation prescribed by optimal complete contracts is sequentially optimal with incomplete contracts if the buyer does not receive too much information ex-interim. We show that the English auction restricts the information optimally.
\end{abstract}

JEL classification: D44, D82, H57

Keywords: Incomplete contracts, repeated relationships, procurement, commitment

\section{INTRODUCTION}

1.1. Motivation and main result. Suppliers of custom made goods and services that fit a buyer's unique need are in long-term relationships with the buyer (e.g., large construction projects, delivery of custom made parts in the automotive industry, or software delivery projects). During the project, external conditions (state of the world) usually change and thereby the cost of the supplier (Bajari et al., 2014). First, external factors outside of the supplier's control (such as steel, energy, concrete, tariffs, labor) drive supplier's input costs. Second, the design of the project may change (e.g., during construction it is discovered that the soil is different than expected).

Even though the change in the environment can have a substantial impact on profitability, contracts typically do not specify how to adjust the initial terms and conditions for every potential state of the world. That is, contracts are incomplete. ${ }^{1}$ Complete contracts in procurement are either too costly (Bajari and Tadelis, 2001), cannot be enforced by courts (Chakravarty and MacLeod, 2009), or require too much knowledge about potential states of the world (Tirole, 2009).

Contractual incompleteness usually comes at a cost. In a state of the world that is not covered by the contract, the buyer and the suppliers need to negotiate new terms. Most of the recent literature focuses on the frictions in such (re-)negotiations (Bajari and Tadelis, 2001; Bajari et al., 2014; Herweg and Schmidt, forthcoming; Herweg and Schwarz, 2018) due to e.g., supplier bargaining

(A1) University of MANnheim And ZEW MANnheim, GRetschKo@ZEW.dE

(A2) University of Bonn, POLLRICH@UNi-BONN.DE

We would like to thank Achim Wambach for helpful comments and discussions.

${ }^{1}$ For a general definition of incomplete contracts and a review of the literature see Hart (2017). 
power or delay. However, there is another potential channel that makes incomplete contracts costly for the buyer: information revelation. During the procurement process, the suppliers place bids based on their private cost information. The buyer can use this information in subsequent renegotiations. This may lower the overall buyer surplus in two ways. First, it imposes a sequential rationality constraint on the mechanism design problem of the buyer. Such a constraint is absent if contracts are complete. Second, as supplier's rents depend on their private information, they will be cautious about what they reveal in the initial procurement. That is, the incentive constraints of the suppliers depend on the information structure of the initial procurement mechanism.

We show that contractual incompleteness does not impose a cost on the buyer. Thus, if writing complete contracts is costly, it is optimal to abstain from doing so. To this end, we derive a buyersurplus optimal mechanism followed by complete contracts and show that the buyer attains the same surplus with incomplete contracts. The problem of finding the optimal mechanism with incomplete contracts is challenging. Any fully-revealing direct mechanism provides too much information in the initial procurement stage. The buyer-surplus optimal allocation is then not sequentially optimal for the buyer. Thus, the revenue equivalence principle does not apply. The buyer needs to manage information revealed by the mechanism. We show that an English auction followed by a take-it-orleave-it offer implements the buyer-surplus optimal allocation and reveals just enough information to satisfy the sequential rationality constraint.

Our analysis of buyer-surplus optimal mechanisms under complete contracting is interesting in its own right. The usual attempt to write complete procurement contracts in a changing environment is to use cost-plus contracts (Bajari and Tadelis, 2001) or price adjustment clauses (Kosmopoulou and Zhou, 2014). Essentially, both ways directly add or subtract any observable cost changes from the initial price. Our analysis reveals that it is optimal for the buyer to be more aggressive and require price adjustments beyond this level.

1.2. Model and intuition. A buyer (she) purchases a project from $n$ symmetric suppliers (he) in two periods. In period one, each supplier privately observes his cost of delivering the project in the initial state of the world. In the second period, a new (publicly observable) state of the world realizes. Supplier's costs in the second period are a function of the first-period costs and the state of the world. Under complete contracting, the buyer chooses a mechanism that pins down allocation and payment conditional on the state of the world for both periods. Under incomplete contracting, the buyer uses a mechanism in period one that pins down allocation and payment for that period only. After observing the outcome of the first mechanism and the realization of the state of the world, she proposes a new contract for period two. 
In Section 3 we derive the buyer-surplus optimal allocation under complete contracting. The optimal first-period allocation maximizes the buyer's dynamic virtual surplus, taking into account virtual surplus in the second period. The optimal second-period allocation maximizes the (static) virtual surplus conditional on the realized state of the world. This implies that the buyer only purchases within a period if the respective virtual surplus is larger than zero. We provide an implementation of the buyer-surplus optimal allocation with spot contracts. The buyer runs a standard auction with a reserve price. The winning supplier receives a call option for second-period production. The strike price of the option depends on the realization of the state of the world. The supplier will exercise the option whenever his second-period costs are below the strike price.

A price adjustment clause or cost-plus contract does not implement the optimal allocation. Both adjust the first-period price directly to the new state of the world. For instance, if the new state of the world is an additive cost shock, this shock is directly added to the initial price. As a consequence, production in period two continues either for all first-period cost types or for none. Our analysis reveals that even if the buyer chooses a supplier in the first period, production in the second period depend on this suppliers first-period cost type. Some cost types are only chosen to continue production in favorable states of the world. Thus, whether production continues in the second period depends not only on the realized state of the world but also on the supplier's first-period cost type.

In Section 4 we show that the buyer-surplus optimal allocation is implementable with incomplete contracts. This requires a different mechanism as the implementation from Section 3 is not sequentially rational. In a monotonic equilibrium, the buyer learns the first-period costs of the suppliers through their bids in the auction and would like to adjust the call option in each realized state of the world. Suppliers anticipate the effect of their bid on the (sequentially optimal) second-period offer, which upsets a potential monotonic equilibrium in the first place.

To implement the buyer-surplus optimal allocation, the buyer needs to restrict her ability to learn from the supplier's bids. We show that an English auction restricts this information effectively. The buyer does not learn the cost of the winning supplier. She merely learns that it falls below the cost of the runner-up. This information allows the buyer to implement the same allocation as the optimal complete contract would. To this end, the buyer observes the realization of the state of the world and makes a take-it-or-leave-it offer to the winning supplier. She is not tempted to make a more aggressive offer as she is still sufficiently uncertain about the winning supplier's costs. 
1.3. Relation to the literature. Beyond the literature on procurement with incomplete contracts as described in Section 1.1, our work is related to the literature on mechanism design without commitment.

Our work is related to Tirole (2016) who points out that with limited commitment there is a difference between negative and positive selection of types. That is, whether in the future the mechanism designer interacts with bad or good types of the agent. He demonstrates for the singleagent case that with positive selection, a lack of commitment is not an issue. We also study a model with positive selection. Future production only takes place if a supplier was chosen. This always renders the buyer more optimistic about the supplier's type. In contrast to Tirole (2016), we consider a multi-agent framework. With multiple agents, an allocation contains more information as in the single-agent case. Thus, it becomes crucial to design the mechanism in such a way that it reveals the right amount of information.

Fugger et al. (2019) consider sequential procurement with private cost shocks in a two-type model. Supplier's costs change between periods. This change is private information of the suppliers. In contrast to the work at hand, their model captures, for example, learning effects rather than a change in input costs or design changes. They compare different auction formats and derive the optimal mechanism under the assumption that the buyer can only negotiate with the winning supplier in the second period. They share the insight that the buyer may benefit from restricting information generated by the initial procurement mechanism. However, in their setting, the full-commitment outcome is not always attainable.

The larger part of the literature on mechanism design without commitment is concerned with negative selection. That is, with a seller designing an auction without commitment to retaining the object when the auction does not allocate it (e.g., when the reserve price is not met). Additional interaction only takes place if the good is not sold. In this case, remaining bidders have low valuations. In contrast to the work at hand, the full-commitment outcome is not attainable. Skreta (2015) analyzes optimal selling mechanisms with a finite horizon. If the good was not allocated in the first stage, the seller proposes a new mechanism. She shows that optimal mechanisms resemble their static counterparts. Liu et al. (2019) study a similar problem but with an infinite horizon. They show that with sufficiently many bidders a version of the Coase conjecture applies and an efficient auction is uniquely optimal. Vartiainen (2013) goes one step further by studying a seller who does not adhere to the mechanism initially proposed irrespective of whether the good was to be sold or not. He proves that the English auction is an optimal mechanism, as it reveals just the 
right amount of information and the seller does not wish to propose an alternative mechanism. ${ }^{2} \mathrm{He}$ is the first to point out this particular feature of the English auction. However, in his setting, the full commitment outcome is not attainable.

\section{MOdel}

A buyer (she) purchases inputs from $n$ ex-ante identical suppliers (he) over two periods. ${ }^{3}$ In period $\tau=1,2$, the buyer demands a quantity $Q_{\tau}$. To economize on notation, we normalize $Q_{1}=1$ and denote by $Q:=Q_{2} / Q_{1}>0$ the relative quantity in the second period. In each period, the buyer has a constant value of $R>0$ per unit of delivery. That is, if the buyer purchases in period $\tau$ at per-unit price $p_{\tau}$, her profit is $Q_{\tau} \cdot\left(R-p_{\tau}\right)$. The buyer can only purchase in the second period if she purchased in period $1 .^{4}$ There is no discounting between periods as any discounting can be incorporated in the parameter $Q$.

Period 1. At the beginning of period 1 each supplier privately learns his period-one production $\operatorname{costs} c_{1}^{i}$. Costs are independently and identically distributed on the interval $[\underline{c}, \bar{c}]$ according to the distribution function $F$ with density $f$ which is bounded away from 0 on $[\underline{c}, \bar{c}]$.

Period 2. At the beginning of the second period, a new state of the world $\omega$ realizes affecting the suppliers' production costs. The buyer and suppliers observe the realization. Denote by $\Omega$ the set of possible states of the world endowed with the Borel $\sigma$-algebra. We make no restrictions on $\Omega$ to capture the richness of factors affecting second-period production costs. Denote by $G: \Omega \rightarrow[0,1]$ the distribution of $\omega$ on $\Omega$. Together with first-period $\operatorname{costs} c_{1}^{i}$, the state of the world $\omega$ determines a supplier's second-period production costs $c_{2}^{i}=k\left(c_{1}^{i}, \omega\right) .{ }^{5}$ We will also refer to $\omega$ as the cost shock. We assume that for all $\omega$ the function $k$ is strictly increasing and differentiable in its first argument, and denote by $k_{c}$ the respective derivative. Further assume that there is a finite number $K \in \mathbb{R}$ such that $0 \leq k_{c}(c, \omega) \leq K$ for all $c \in[\underline{c}, \bar{c}]$ and all $\omega \in \Omega$.

Our assumptions on second-period production costs cover two prominent examples: (i) additive shocks, where $k(c, \omega)=c+\omega$, and (ii) multiplicative shocks, where $k(c, \omega)=c \cdot \omega$. The cost shock affects the absolute values of second-period production cost, but does not alter the ranking of suppliers in terms of efficiency.

\footnotetext{
${ }^{2}$ Note that this is not trivial in the setting at hand. The buyer cannot arbitrarily restrict information, as she needs to make a payment to the supplier in period one. Thus, she cannot use an intermediary that retains all information generated by the mechanism.

${ }^{3}$ We can straightforwardly extend our analysis to an arbitrary (finite) number of periods, without affecting our main insight on the optimality of incomplete contracts.

${ }^{4}$ This assumption is inconsequential as we would get similar results allowing for periods to be independent. The current formulation is a good representation of real-life procurement.

${ }^{5}$ We can extend our analysis to the case where the buyer's per-unit valuation $R$ also depends on the period and the realization of the state of the world $\omega$. This would not affect our main insights.
} 
Timing of events. We briefly describe the timing of events. A precise definition of the mechanisms is in Section 3 and Section 4. With complete contracts, the buyer posts a mechanism in period one. The mechanism specifies allocation and payment for both periods taking into account all possible realizations of the state of the world $\omega$.

With incomplete contracts, the period-one mechanism merely specifies allocation and payments for that period. At the beginning of the second period and after the state of the world realized the buyer proposes a second-period mechanism, specifying allocation and payments for that period. The buyer's second-period proposal, in particular, takes into account any information revealed from playing the first-period mechanism. ${ }^{6}$

Throughout the manuscript we maintain the following technical assumptions.

Assumption 1. The following holds true

(i) The first-period virtual cost $\Psi_{1}(c):=c+\frac{F(c)}{f(c)}$ is non-decreasing in $c$,

(ii) The second-period virtual cost $\Psi_{2}(c, \omega):=k(c, \omega)+\frac{F(c)}{f(c)} k_{c}(c, \omega)$ is non-decreasing in $c$ for all $\omega$.

A sufficient condition for Assumption 1 is that $F(c) / f(c)$ is increasing and $k(c, \omega)$ is convex in $c$. With an additive or multiplicative cost shock condition (ii) of Assumption 1 is implied by condition (i), which itself is standard in the literature.

\section{Optimal Procurement With COMPlete CONTRACTS}

Buyer-surplus optimal mechanism. In this section, we assume the buyer can write complete contracts covering both periods. Invoking a revelation principle allows us to focus on direct and incentive-compatible mechanisms. A direct mechanism consists of (i) a first-period allocation rule $x_{1}:[\underline{c}, \bar{c}]^{n} \rightarrow \Delta\{0,1, \ldots, n\}$, (ii) a second-period allocation rule $x_{2}:[\underline{c}, \bar{c}]^{n} \times \Omega \rightarrow \Delta\{0,1, \ldots, n\}$, and (iii) a transfer rule $t:[\underline{c}, \bar{c}]^{n} \rightarrow \mathbb{R}^{7}$ Each supplier reports a first-period cost to the mechanism. The mechanism selects a supplier for the first period according to $x_{1}$, the supplier for the second period according to $x_{2}$, and determines a transfer for each supplier according to $t .^{8}$

\footnotetext{
${ }^{6}$ All suppliers participate in the second period as we want to abstract from supplier bargaining power and the hold-up problem. We solely focus on the problem of information revelation. Competition in the second period is a way to achieve that.

${ }^{7}$ As contracts are complete and $\omega$ is publicly observable, it is without loss that all transfers are made in the first period. In this case, $\omega$ is integrated out, and the transfer does not depend on $\omega$.

${ }^{8}$ There is no need to ask for reports in period two. As the state of the world is publicly observable no new private information arises.
} 
In order to establish the allocation that maximizes buyer surplus over both periods, we introduce the following values. We define $c_{1}^{\star}$ as the (unique) solution to

$$
\Psi_{1}\left(c_{1}^{\star}\right)=R+\int_{\Omega} Q \max \left\{0, R-\Psi_{2}\left(c_{1}^{\star}, \omega\right)\right\} d G(\omega)
$$

whenever it exists and by $c_{1}^{\star}=\bar{c}$ otherwise. For all $\omega$ we define $c_{2}^{\star}(\omega)$ as the (unique) solution to

$$
\Psi_{2}\left(c_{2}^{\star}(\omega), \omega\right)=R
$$

whenever it exists and by $c_{2}^{\star}(\omega)=\bar{c}$ otherwise.

Proposition 1. The allocation that maximizes the buyer surplus is given by ${ }^{9}$

$$
x_{1}^{i}\left(c_{1}^{1}, \ldots, c_{1}^{n}\right)= \begin{cases}1, & c^{i}=\min \left\{c^{1}, \ldots, c^{n}\right\} \text { and } c^{i} \leq c_{1}^{\star} \\ 0, & \text { else }\end{cases}
$$

and

$$
x_{2}^{i}\left(c_{1}^{1}, \ldots, c_{1}^{n}, \omega\right)= \begin{cases}1, & c^{i}=\min \left\{c^{1}, \ldots, c^{n}\right\} \text { and } k\left(c^{i}, \omega\right) \leq k\left(c_{2}^{\star}(\omega), \omega\right) \\ 0, & \text { else }\end{cases}
$$

All proofs are in the appendix. In the first period, it is optimal to purchase from the supplier who maximizes the dynamic virtual buyer surplus as long as this is larger than zero. This is reflected in the definition of $c_{1}^{\star}$. Due to the symmetric prior and Assumption 1, the supplier with the lowest first-period cost is also the supplier who yields the highest dynamic virtual buyer surplus. In the second period, it is optimal to purchase from the supplier who maximizes the virtual buyer surplus in the second period as long this is larger than 0 . This is reflected in the definition of $c_{2}^{\star}$. Due to Assumption 1 and the symmetric prior, this is the supplier with the lowest second-period cost. As second-period costs are an increasing function of the first-period cost, the optimal allocation selects the same supplier in both periods whenever there is production in period two.

Implementation with standard auction and spot contracts. In this section, we describe an indirect implementation of the allocation described in Proposition 1. We want to shed light on the optimality of prevalent practices in real-life procurement like price adjustment clauses and cost-plus contracts. Both have in common that payments, unlike in the optimal direct mechanism, are not frontloaded but realize over time.

\footnotetext{
${ }^{9}$ As ties occur with probability 0 we omit the tie-breaking rule from the definition below. For example, choosing a supplier at random in case of a tie is a rule consistent with the buyer-surplus optimal allocation.
} 
One key finding of Proposition 1 is that switching the supplier between periods is never optimal. This suggests an implementation with an auction and option contracts. In period one, the buyer runs an auction among all $n$ suppliers. The supplier who wins the auction is selected for production in period one. In period two, the winning supplier receives an option to continue production at a strike price. $^{10}$

In the following we use the term standard auction as defined in the literature. ${ }^{11}$ In a standard auction, all suppliers are asked to submit bids. The lowest bidder wins the auction. The vector of bids determines the payments to each supplier. To induce different levels of participation, the buyer uses auctions with a reserve price. In period two, the winning supplier faces the option to continue production. The strike price depends on the realized state $\omega$.

Proposition 2. Define $c_{1}^{\star}$ and $c_{2}^{\star}(\omega)$ as in equation (1) and equation (2). Consider the following procedure.

(i) In the first period, the buyer runs a standard auction with reserve price. The winner produces in the first period and receives a set of option contracts.

(ii) In the second period, for each $\omega \in \Omega$ the winner decides whether to commence production at strike price $k\left(c_{2}^{\star}(\omega), \omega\right)$.

In any symmetric and increasing equilibrium that induces all types below $c_{1}^{\star}$ to participate, the buyer surplus equals the maximal surplus determined in Proposition 1.

If the buyer can write complete contracts, revenue equivalence obtains. The option price in period two only depends on the state $\omega$, but not on the outcome of the auction. A winning supplier produces in period one and receives his expected continuation profit. As the latter does not depend on the auction outcome, a supplier's cost-type can be rewritten to include this profit. With this reduction, our setting becomes essentially equivalent to a static auction environment. The reserve price takes future profits of the buyer into account and is more lenient as compared to the static (single-period) reserve price.

Comparing Proposition 2 to price adjustment clauses and cost-plus contracts reveals a significant difference. In the setting at hand, cost-plus contracts and price adjustment clauses boil down to the winning supplier receiving $k\left(p_{1}, \omega\right)$ in the second period if $p_{1}$ is the first-period price or in a termination of production. That is, production continues for all first-period cost types or none. Our analysis reveals that optimally the potential for shut-down of projects between periods one and two

\footnotetext{
${ }^{10}$ The literature on sequential screening refers to such contracts as option contracts. See for instance Courty and Li (2000) and (Börgers, 2015, chapter 11).

${ }^{11}$ See for example Krishna (2009).
} 
depends not only on the realized state of the world but also on the first-period cost type of the supplier. This is a consequence of $c_{2}^{\star}(\omega) \neq c_{1}^{\star}$. In period one, the buyer takes into account the cost shock in period two. She sets a reserve price above the optimal static reserve price, leading to more production in the first period, in the hope for lower cost realizations in period two. However, if costs remain high, she shuts down production in period two for high-cost types.

We conclude this section with an example stating the equilibria for first- and second-price auctions that satisfy the assumptions of Proposition 2.

Example 1. In both auctions, the buyer sets the reserve price

$$
r=c_{1}^{\star}-\int_{\Omega} Q \max \left\{0, k\left(c_{2}^{\star}(\omega), \omega\right)-k\left(c_{1}^{\star}, \omega\right)\right\} d G(\omega) .
$$

In a second-price auction, suppliers follow the bidding strategy $\beta^{S P}:[\underline{c}, \bar{c}] \rightarrow \mathbb{R}$, with

$$
\beta^{S P}(c)=c-\int_{\Omega} Q \max \left\{0, k\left(c_{2}^{\star}(\omega), \omega\right)-k(c, \omega)\right\} d G(\omega) .
$$

In the first price auction, suppliers follow the bidding strategy $\beta^{F P}:[\underline{c}, \bar{c}] \rightarrow \mathbb{R}$, with

$$
\beta^{F P}(c)=\beta^{S P}(c)+\int_{c}^{c_{1}^{\star}} \frac{H(s)}{H(c)} \int_{\left\{\omega: k(s, \omega) \leq k\left(c_{2}^{\star}(\omega), \omega\right)\right\}} Q k_{c}(s, \omega) \mathrm{d} G(\omega) \mathrm{d} s .
$$

\section{Optimal procurement With incomplete CONTRACTS}

The strike option in Proposition 2 depends on the realization $\omega$. Thus, the optimal implementation with spot contracts requires to write contracts in period one for each possible realization of $\omega$ in period two. We call such contracts complete contracts and turn our attention to the case where such contracts are not feasible. That is, the buyer needs to negotiate prices in the second period after observing the bid in the auction and the realization of the state of the world. Given this information, she may want to implement a different contract as prescribed in Proposition 2.

Example 2. Consider the implementation with a standard auction as in Proposition 2. Suppose the suppliers follow a monotonic bidding strategy. As the buyer observes the bids, she can back out the first-period cost $c_{\min }^{1}$ of the winner. Thus, offering a price equal to $k\left(c_{2}^{\star}(\omega), \omega\right)$ is not sequentially optimal for the buyer. She can extract all surplus in period two by offering $k\left(c_{\min }^{1}, \omega\right)$ (if $\left.k\left(c_{\text {min }}^{1}, \omega\right) \leq R\right)$ to the winning supplier from the first-period. This neither implements the optimal allocation, nor does it preserve the proposed equilibrium of the auction.

In any direct mechanism that implements the optimal first-period allocation, the buyer receives more information about the supplier's cost types and is tempted to use this information in the second period. In a monotonic equilibrium of a standard auction, the buyer learns the exact first-period 
cost types. However, to implement the buyer-surplus optimal allocation, it is sufficient to identify the supplier with the lowest first-period cost. Thus, the way forward is to restrict the ability of the buyer to learn from the auction.

An indirect implementation that restricts the information of the buyer is the English auction: the price begins at the reserve price with all suppliers "in". Suppliers may then exit observably and irreversibly as the price drops continuously and endogenously. The auction ends when only one supplier remains, with this supplier winning the auction and receiving the price at which his final opponent quit. ${ }^{12}$ The buyer observes the price at which the second-to-last bidder dropped out but not how much longer the winner planed to stay in the auction. We consider the following timing.

(1) Suppliers participate in an English auction.

(2) The buyer observes the drop-out prices.

(3) First-period production and payments realize.

(4) The buyer and the suppliers observe the realization of $\omega$.

(5) The buyer makes a take-it-or-leave-it offer to the winner of the auction. ${ }^{13}$

(6) Second-period production and payments realize.

The following proposition establishes that an English auction with appropriately chosen reserve price implements the optimal buyer surplus even if complete contracts are not feasible.

Proposition 3. Let $p_{1}$ denote the first-period price. An English auction in the first period with reserve price $r^{\star}=c_{1}^{\star}$ followed by a take-it-or-leave-it offer

$$
p_{2}\left(\omega, p_{1}\right)=\min \left\{k\left(p_{1}, \omega\right), k\left(c_{2}^{\star}(\omega), \omega\right)\right\}
$$

in the second period implements the optimal buyer surplus from Proposition 1.

In the first period, suppliers stay in the auction until the price is equal to their first-period costs. That is, suppliers follow a bidding strategy $\beta^{E}:[\underline{c}, \bar{c}] \rightarrow \mathbb{R}$, with $\beta^{E}(c)=c$. In the second period, the winning supplier accepts if the offer is above his second-period costs. That is, if $p_{2}\left(\omega, p_{1}\right) \geq k(c, \omega)$. Offering $p_{2}\left(\omega, p_{1}\right)$ is optimal for the principal given her second-period belief.

The English auction implements the optimal allocation in equilibrium. The main feature of the English auction is that even though bidding is strictly monotone, the buyer cannot infer the cost type of the winner. The buyer learns from the drop-out prices that the cost of the winning supplier is below the final price in the auction $p_{1}$. In particular, the buyer's belief about the first-period

\footnotetext{
${ }^{12}$ If at some point in the auction, all remaining suppliers quit simultaneously, one of these suppliers is selected at random and named the winner at his exit price.

${ }^{13}$ As will be seen below restricting the buyer to take-it-or-leave-it-offers to the winner is without loss.
} 
cost of the winner is a right-truncation of her prior. Based on this information and the realized state $\omega$, the buyer makes a take-it-or-leave-it offer to the winner. To see that with such an offer, it is sequentially rational to implement the complete-contract allocation consider the following. The buyer's second-period profit is a strictly concave function of the offer (Assumption 1) and $k\left(c_{2}^{\star}(\omega), \omega\right)$ is the unique maximizer against the prior. That is, the buyer does not trade with suppliers with second-period costs above $k\left(c_{2}^{\star}(\omega), \omega\right)$. A right-truncation does not alter the curvature of the buyer's second-period profit function. Thus, if $k\left(c_{2}^{\star}(\omega), \omega\right)$ is below $k\left(p_{1}, \omega\right)$, excluding suppliers with cost above $k\left(c_{2}^{\star}(\omega), \omega\right)$ remains optimal. Loosely speaking, the buyer's posterior belief after the auction excludes supplier types with which trade would not have been optimal regardless. If $k\left(c_{2}^{\star}(\omega), \omega\right)$ is above $k\left(p_{1}, \omega\right)$, the profit function is increasing on the entire support of the truncation and thus the corner $k\left(p_{1}, \omega\right)$ is the unique maximizer.

To see that truthful bidding is an equilibrium consider the profit of the buyer at each point of the auction. If a supplier wins the auction at a price $p_{1}<c_{1}$, the buyer will offer $\min \left\{k\left(p_{1}, \omega\right)\right.$, $\left.k\left(c_{2}^{\star}(\omega), \omega\right)\right\}<k\left(c_{1}, \omega\right)$ in the second period. The supplier's overall profit is then strictly negative as he will reject the buyer's offer. If a supplier wins the auction at a price $p_{1}>c_{1}$ she makes a positive profit in period one, and the profit in the second period is always non-negative. Thus, following the usual logic of the English auction, staying in the auction until the price reaches first-period costs is optimal for the suppliers. Overall, we argued that the English auction implements the buyer-surplus maximizing allocation. In the appendix, we show that suppliers expected utilities are the same as in the complete-contracts case and thus also buyer surplus coincides.

\section{Discussion}

An English auction with a reserve price an a subsequent take-it-or-leave-it offer implements the same outcome as the optimal complete contracts would. The English auction is not the unique mechanism that yields the maximal buyer surplus when complete contracts are not feasible. However, alternative mechanisms require a third party controlling the information flow between the buyer and the suppliers. Consider a second-price auction run by an intermediary. The buyer learns the winning supplier's identity and his payment, but not the vector of submitted bids. This auction yields the same information for the buyer as the English auction presented above. It is straightforward to verify that it implements the optimal buyer surplus. ${ }^{14}$

\footnotetext{
${ }^{14}$ There are many other alternatives, for instance, a $k$-th price auction that additionally reveals the second-lowest bid. Also, a $k$-th price auction followed by a second-price auction in period two among the $k$ lowest bidders works as well.
} 
Our insights extend beyond two periods. In this case, it remains optimal to select a supplier in the first-period via the English auction. In the subsequent periods, the buyer presents the winning supplier with a series of take-it-or-leave-it offers. The offers become more aggressive over time. This observation reinforces the insight that cost-plus contracts and price adjustment clauses are not optimal even when complete contracts are feasible.

The limiting assumption in this manuscript is that suppliers do not receive idiosyncratic private information over time. ${ }^{15}$ If this where the case, it is no longer optimal to purchase from the same supplier in both periods. The cost shock may change the identity of the low-cost supplier between periods. Thus, for subsequent implementation, not only information revealed about the winner but all suppliers becomes relevant. This renders implementation more challenging. We consider an instance of this problem in Fugger et al. (2019).

\section{REFERENCES}

Bajari, P., S. Houghton, And S. Tadelis (2014): "Bidding for Incomplete Contracts: An Empirical Analysis of Adaptation Costs," American Economic Review, 104, 1288-1319.

Bajari, P. And S. TAdelis (2001): "Incentives versus Transaction Costs: A Theory of Procurement Contracts," RAND Journal of Economics, 32, 387-407.

Börgers, T. (2015): An introduction to the theory of mechanism design, Oxford University Press, USA.

Chakravarty, S. And W. B. MacLeod (2009): "Contracting in the Shadow of the Law," RAND Journal of Economics, 40, 533-557.

Courty, P. And H. Li (2000): "Sequential Screening," Review of Economic Studies, 697-717.

Fugger, N., V. Gretschko, And M. Pollrich (2019): "Sequential Procurement without Commitment," mimeo.

Hart, O. (2017): "Incomplete Contracts and Control," American Economic Review, 107, 1731-52.

Herweg, F. And K. M. Schmidt (forthcoming): "Procurement with Unforeseen Contingencies," Management Science.

Herweg, F. And M. A. Schwarz (2018): "Optimal Cost Overruns: Procurement Auctions with Renegotiation," International Economic Review, 59, 1995-2021.

Kosmopoulou, G. And X. Zhou (2014): "Price Adjustment Policies in Procurement Contracting: An Analysis of Bidding Behavior," The Journal of Industrial Economics, 62, 77-112.

\footnotetext{
${ }^{15}$ Our results remain valid when the cost shock is the same for all suppliers but unobservable to the buyer. In this case, the buyer extracts the suppliers' symmetric private information for free, for instance with a shoot-the-liar mechanism.
} 
Krishna, V. (2009): Auction Theory, Burlington: Academic Press.

Liu, Q., K. Mierendorff, X. Shi, and W. Zhong (2019): "Auctions with Limited Commitment," American Economic Review, 109, 876-910.

Riley, J. And R. Zeckhauser (1983): "Optimal Selling Strategies: When to Haggle, when to Hold Firm," The Quarterly Journal of Economics, 98, 267-289.

Skreta, V. (2015): "Optimal Auction Design under Non-Commitment," Journal of Economic Theory, 159, 854-890.

Tirole, J. (2009): "Cognition and incomplete contracts," American Economic Review, 99, 265-94. (2016): "From Bottom of the Barrel to Cream of the Crop: Sequential Screening with Positive Selection," Econometrica, 84, 1291-1343.

VARTiAinen, H. (2013): "Auction design without commitment," Journal of the European Economic Association, 11, 316-342.

\section{Appendix A. Omitted Proofs}

\section{A.1. Proof of Proposition 1.}

Proof. For $i \in\{1, \ldots, n\}$ and $c \in[\underline{c}, \bar{c}]$ let $T^{i}(c):=\mathbb{E}\left[t^{i}\left(c, C^{-i}\right)\right], X_{1}^{i}(c):=\mathbb{E}\left[x_{1}^{i}\left(c, C^{-i}\right)\right]$ and $X_{2}^{i}(c, \omega):=\mathbb{E}\left[x_{2}^{i}\left(c, C^{-i}, \omega\right)\right]$ denote the respective expected transfer and allocation probabilities from supplier $i$ 's perspective, conditional on other suppliers' (truthful) reports. Define supplier $i$ 's expected profit when his period-one production costs are $c$ but he reports $c^{\prime}$ to the mechanism, while all other suppliers report truthfully:

$$
U^{i}\left(c, c^{\prime}\right):=T^{i}\left(c^{\prime}\right)-X_{1}^{i}\left(c^{\prime}\right)\left(c+\int_{\Omega} Q k(c, \omega) X_{2}^{i}\left(c^{\prime}, \omega\right) \mathrm{d} G(\omega)\right) .
$$

Further denote $U^{i}(c):=U^{i}(c, c)$ the expected profit from reporting truthfully. A direct mechanism is incentive compatible whenever for all $i \in\{1, \ldots, n\}$ and all $c, c^{\prime} \in[\underline{c}, \bar{c}]$ we have $U^{i}(c) \geq U^{i}\left(c, c^{\prime}\right)$. A direct mechanism is individually rational whenever $U^{i}(c) \geq 0$ for all $c, i$. The following lemma gives a characterization of incentive compatible and individually rational mechanisms.

Lemma 1. If a direct mechanism is incentive compatible, then

$$
U^{i}(c)=U^{i}(\bar{c})+\int_{c}^{\bar{c}} X_{1}^{i}(s)\left(1+\int_{\Omega} Q k_{c}(s, \omega) X_{2}^{i}(s, \omega) \mathrm{d} G(\omega)\right) \mathrm{d} s .
$$

An incentive compatible direct mechanism is individually rational, if for all $i$

$$
U^{i}(\bar{c}) \geq 0
$$


Proof. Incentive compatibility implies for all $c<c^{\prime}$

$$
\begin{aligned}
U^{i}(c) & \geq T^{i}\left(c^{\prime}\right)-X_{1}^{i}\left(c^{\prime}\right)\left(c+\int_{\Omega} Q k(c, \omega) X_{2}^{i}\left(c^{\prime}, \omega\right) \mathrm{d} G(\omega)\right) \\
& =U^{i}\left(c^{\prime}\right)-X_{1}^{i}\left(c^{\prime}\right)(\underbrace{c-c^{\prime}}_{<0}+\int_{\Omega} Q \underbrace{\left(k(c, \omega)-k\left(c^{\prime}, \omega\right)\right)}_{<0} X_{2}^{i}\left(c^{\prime}, \omega\right) \mathrm{d} G(\omega)) \\
& \geq U^{i}\left(c^{\prime}\right) .
\end{aligned}
$$

Hence, $U^{i}(c)$ is a non-increasing function on the compact interval $[\underline{c}, \bar{c}]$, and is therefore differentiable almost everywhere. Individual rationality for all types $c \in[\underline{c}, \bar{c}]$ is thus implied by $U^{i}(\bar{c}) \geq 0$. Invoking once more incentive compatibility, we get for $c>c^{\prime}$

$$
\begin{aligned}
-X_{1}^{i}(c)\left(1+\int_{\Omega} Q \frac{k(c, \omega)-k\left(c^{\prime}, \omega\right)}{c-c^{\prime}}\right. & \left.X_{2}^{i}(c, \omega) \mathrm{d} G(\omega)\right) \geq \frac{U^{i}(c)-U^{i}\left(c^{\prime}\right)}{c-c^{\prime}} \\
& \geq-X_{1}^{i}\left(c^{\prime}\right)\left(1+\int_{\Omega} Q \frac{k(c, \omega)-k\left(c^{\prime}, \omega\right)}{c-c^{\prime}} X_{2}^{i}\left(c^{\prime}, \omega\right) \mathrm{d} G(\omega)\right)
\end{aligned}
$$

Taking the limit as $c \rightarrow c^{\prime}$ (resp. $c^{\prime} \rightarrow c$ ) yields

$$
\frac{\partial U}{\partial c}=-X_{1}^{i}(c)\left(1+\int_{\Omega} Q k_{c}(c, \omega) X_{2}^{i}(c, \omega) \mathrm{d} G(\omega)\right)
$$

whenever this derivative exists. Note that in the integrals on the left- and right-hand side we can interchange the order of limit and integration because $k(c, \omega)$ is uniformly bounded. Finally equation (5) follows from the fundamental theorem of calculus.

Using Lemma 1 and integration by parts we can express the buyer surplus from an incentive compatible mechanism as follows:

$$
\begin{aligned}
\int \cdots & \int_{\underline{c}}^{\bar{c}}\left[\sum_{i=1}^{n} R x_{1}^{i}\left(c^{1}, \ldots, c^{n}\right)+\right. \\
& \left.\int_{\Omega} Q R x_{2}^{i}\left(c^{1}, \ldots, c^{n}, \omega\right)-t^{i}\left(c^{1}, \ldots, c^{n}\right)\right] \mathrm{d} F\left(c^{1}\right) \cdots \mathrm{d} F\left(c^{n}\right) \\
=\quad \int \cdots & \int_{\underline{c}}^{\bar{c}} \sum_{i=1}^{n} x_{1}^{i}\left(c^{1}, \ldots, c^{n}\right)\left\{R-\Psi_{1}\left(c^{i}\right)\right. \\
& \left.+\int_{\Omega} Q x_{2}^{i}\left(c^{1}, \ldots, c^{n}, \omega\right)\left(R-\Psi_{2}\left(c^{i}, \omega\right)\right) d G(\omega)\right\} \mathrm{d} F\left(c^{1}\right) \cdots \mathrm{d} F\left(c^{n}\right) .
\end{aligned}
$$

Pointwise maximization yields the (desired) optimal values for $x_{t}^{i}$.

It remains to be shown that there is a transfer rule $t$ that renders the described allocation incentive compatible. Define for every $c \leq c_{1}^{\star}$ the set $A(c):=\left\{\omega \mid R-\Psi_{2}(c, \omega) \geq 0\right\}$. The set $A(c)$ contains the 
values of the cost-shock $\omega$ for which production in period two continues given the first-period cost of the winner are $c$. As $\Psi(c, \omega)$ decreases in $c, A(c) \subseteq A\left(c^{\prime}\right)$ for all $c>c^{\prime}$. Let $H(c)=(1-F(c))^{n-1}$ and define the transfer rule as

$$
T(c):=\left\{\begin{array}{rr}
H(c)\left(c+\int_{A(c)} Q k(c, \omega) \mathrm{d} G(\omega)\right) & \\
\quad+\int_{c}^{c_{1}^{\star}} H(s)\left(1+Q \int_{A(s)} k_{c}(s, \omega) d G(\omega)\right) \mathrm{d} s, & c \leq c_{1}^{\star}, \\
0, & c>c_{1}^{\star},
\end{array}\right.
$$

and let $t^{i}\left(c^{1}, \ldots, c^{n}\right)=T\left(c^{i}\right)$ for all $\left(c^{1}, \ldots, c^{n}\right)$. We verify that together with this transfer rule the mechanism that implements the optimal allocation is indeed incentive compatible. As the mechanism is symmetric, we drop the superscript for the bidder's identity. For all $c$ we have $U(c)=T(c)-H(c)\left[c+\int_{A(c)} Q k(c, \omega) \mathrm{d} G(\omega)\right] \geq 0$, hence all supplier types are willing to participate in the mechanism. The latter also implies that no type strictly prefers reporting an untruthful value $c^{\prime}>c_{1}^{\star}$. Now fix some $c \leq c_{1}^{\star}$. Reporting $c^{\prime} \leq c_{1}^{\star}$ instead, yields

$$
U\left(c, c^{\prime}\right)=T\left(c^{\prime}\right)-H\left(c^{\prime}\right)\left(c+\int_{A\left(c^{\prime}\right)} Q k(c, \omega) d G(\omega)\right) .
$$

Hence, $U(c, c)-U\left(c, c^{\prime}\right)$ is equal to

$$
\begin{aligned}
& \int_{c}^{c_{1}^{\star}} H(s)\left(1+Q \int_{A(s)} k_{c}(s, \omega) d G(\omega)\right) \mathrm{d} s-H\left(c^{\prime}\right)\left(c^{\prime}+\int_{A\left(c^{\prime}\right)} Q k\left(c^{\prime}, \omega\right) \mathrm{d} G(\omega)\right) \\
& -\int_{c^{\prime}}^{c_{1}^{\star}} H(s)\left(1+Q \int_{A(s)} k_{c}(s, \omega) \mathrm{d} G(\omega)\right) \mathrm{d} s+H\left(c^{\prime}\right)\left(c+\int_{A\left(c^{\prime}\right)} Q k(c, \omega) \mathrm{d} G(\omega)\right) \\
= & \int_{c^{\prime}}^{c} H\left(c^{\prime}\right)-H(s) \mathrm{d} s+H\left(c^{\prime}\right) \int_{A\left(c^{\prime}\right)} Q\left(k(c, \omega)-k\left(c^{\prime}, \omega\right)\right) \mathrm{d} G(\omega) \\
= & \int_{c^{\prime}}^{c} H(s) Q \int_{A(s)} k_{c}(s, \omega) \mathrm{d} G(\omega) d s \\
= & \int_{c^{\prime}}^{c} H\left(c^{\prime}\right)-H(s) d s+\int_{A\left(c^{\prime}\right)}^{c} H\left(c^{\prime}\right) Q \int_{c^{\prime}}^{c} k_{c}(s, \omega) \mathrm{d} s \mathrm{~d} G(\omega) \\
& -\int_{c^{\prime}}^{c} H(s) Q \int_{A(s)} k_{c}(s, \omega) \mathrm{d} G(\omega) \mathrm{d} s \\
\geq & \int_{c^{\prime}}^{c} H\left(c^{\prime}\right)-H(s) \mathrm{d} s+\int_{c^{\prime}}^{c}\left(H\left(c^{\prime}\right)-H(s)\right) \int_{A(s)}^{c} H\left(c^{\prime}\right) Q \int_{A\left(c^{\prime}\right)} k_{c}(s, \omega) \mathrm{d} G(\omega) \mathrm{d} s
\end{aligned}
$$


The penultimate inequality follows from $A(s) \subseteq A\left(s^{\prime}\right)$ for all $s>s^{\prime}$ and from $k_{c} \geq 0$. Finally, a supplier's payoff with true $\operatorname{cost} c>c_{1}^{\star}$ is negative when he reports $c^{\prime} \leq c$ instead. Hence, the described direct mechanism is indeed incentive compatible. It implements the buyer-surplus optimal allocation and achieves the maximal buyer surplus.

\section{A.2. Proof of Proposition 2.}

Proof. We start in period two. The strike prices depends on $\omega$, but not on the auction outcome in period one. Hence, the winning supplier continues production in state $\omega$ if and only of $k(c, \omega) \leq$ $k\left(c_{2}^{\star}(\omega), \omega\right)$. Let denote $\Omega(c):=\left\{\omega \mid k(c, \omega) \leq k\left(c_{2}^{\star}(\omega), \omega\right)\right\}$ the set of states in which first-period cost type $c$ continues production in period two. ${ }^{16}$ Define the function $\Phi(c):=\int_{\Omega} Q \max \left\{0, k\left(c_{2}^{\star}(\omega), \omega\right)-\right.$ $k(c, \omega)\} \mathrm{d} G(\omega)$, the expected second-period profit of a supplier with first-period cost $c$. The following lemma will prove useful in the remainder.

Lemma 2. For every $c \in[\underline{c}, \bar{c}]$ we have that

$$
\Phi(c)=\Phi(\underline{c})+\int_{\underline{c}}^{c} \varphi(s) \mathrm{d} s
$$

with

$$
\varphi(c)=-\int_{\Omega(c)} Q k_{c}(c, \omega) \mathrm{d} G(\omega) .
$$

Proof. The function $\Phi$ is continuous and non-increasing, thus absolutely continuous and almosteverywhere differentiable. Denote $\varphi$ the derivative, and set $\varphi(c)=0$ wherever the derivative does not exist. Equality (7) follows from the fundamental theorem of calculus. To verify (8) let $c>c^{\prime}$ and note that $\Omega(c) \subset \Omega\left(c^{\prime}\right) \subset \Omega$. We then have

$$
\begin{aligned}
& \Phi(c)-\Phi\left(c^{\prime}\right) \\
= & Q \int_{\Omega} \max \left\{0, k\left(c_{2}^{\star}(\omega), \omega\right)-k(c, \omega)\right\}-\max \left\{0, k\left(c_{2}^{\star}(\omega), \omega\right)-k\left(c^{\prime}, \omega\right)\right\} \mathrm{d} G(\omega) \\
= & -Q \int_{\Omega(c)} k(c, \omega)-k\left(c^{\prime}, \omega\right) \mathrm{d} G(\omega)-Q \int_{\Omega\left(c^{\prime}\right) \backslash \Omega(c)} k\left(c_{2}^{\star}(\omega), \omega\right)-k\left(c^{\prime}, \omega\right) \mathrm{d} G(\omega) \\
\leq & -Q \int_{\Omega(c)} k(c, \omega)-k\left(c^{\prime}, \omega\right) \mathrm{d} G(\omega)
\end{aligned}
$$

Dividing by $c-c^{\prime}>0$ yields

$$
\frac{\Phi(c)-\Phi\left(c^{\prime}\right)}{c-c^{\prime}} \leq-Q \int_{\Omega(c)} \frac{k(c, \omega)-k\left(c^{\prime}, \omega\right)}{c-c^{\prime}} \mathrm{d} G(\omega) .
$$

\footnotetext{
$\overline{{ }^{16} \text { Notice that }} \Omega(c)=A(c)$, where $A(c)$ was defined in the proof of Proposition 1.
} 
Taking the limit $c^{\prime} \rightarrow c$ yields (we can interchange the limit with the integral because $k_{c}(\cdot, \omega)$ is uniformly bounded) $\Phi^{\prime}(c) \leq \varphi(c)$ wherever the derivative exists. Similarly, we have that

$$
\begin{aligned}
& \Phi(c)-\Phi\left(c^{\prime}\right) \\
= & -Q \int_{\Omega(c)} k(c, \omega)-k\left(c^{\prime}, \omega\right) \mathrm{d} G(\omega)-Q \int_{\Omega\left(c^{\prime}\right) \backslash \Omega(c)} k\left(c_{2}^{\star}(\omega), \omega\right)-k\left(c^{\prime}, \omega\right) \mathrm{d} G(\omega) \\
\geq & -Q \int_{\Omega\left(c^{\prime}\right)} k(c, \omega)-k\left(c^{\prime}, \omega\right) \mathrm{d} G(\omega) .
\end{aligned}
$$

Dividing by $c-c^{\prime}$ and taking the limit $c \rightarrow c^{\prime}$ yields $\Phi^{\prime}(c) \geq \varphi(c)$ wherever the derivative exists. We have thus confirmed (8).

Now consider a symmetric equilibrium with decreasing bids. Denote $m(c)$ the expected payment to type $c$ in this equilibrium. By assumption $m(c)=0$ when $c>c_{1}^{\star}$. To guarantee participation for types $c \leq c_{1}^{\star}$ only, it has to hold that

$$
m\left(c_{1}^{\star}\right)=H\left(c_{1}^{\star}\right)\left(c_{1}^{\star}-\Phi\left(c_{1}^{\star}\right)\right)
$$

If type $c$ mimicks the strategy of type $c^{\prime}$ his expected payoff is

$$
\Pi\left(c \mid c^{\prime}\right)=H\left(c^{\prime}\right)(-c+\Phi(c))+m\left(c^{\prime}\right)
$$

The equilibrium condition then reads as

$$
\frac{\mathrm{d} m(c)}{\mathrm{d} c}=h(c)(c-\Phi(c))
$$

Hence,

$$
m(c)= \begin{cases}0, & c>c_{1}^{\star}, \\ H\left(c_{1}^{\star}\right)\left(c_{1}^{\star}-\Phi\left(c_{1}^{\star}\right)\right)-\int_{c}^{c_{1}^{\star}} h(s) s \mathrm{~d} s+\int_{c}^{c_{1}^{\star}} h(s) \Phi(s) \mathrm{d} s, & c \leq c_{1}^{\star}\end{cases}
$$

Note that $m(c)$ does not depend on the auction format. Hence, the buyer surplus is the same in each symmetric and strictly decreasing equilibrium with the same level of participation.

To complete the proof notice that the described equilibria implement the allocation identified in Proposition 1. Using integration by parts and Lemma 2, a supplier's expected utility from participation when his cost is $\mathrm{c}$ is given by

$$
\begin{aligned}
U(c) & =H(c)(-c+\Phi(c))+H\left(c_{1}^{\star}\right)\left(c_{1}^{\star}-\Phi\left(c_{1}^{\star}\right)\right)-\int_{c}^{c_{1}^{\star}} h(s) s \mathrm{~d} s+\int_{c}^{c_{1}^{\star}} h(s) \Phi(s) \mathrm{d} s \\
& =\int_{c}^{c_{1}^{\star}} H(s) \mathrm{d} s+\int_{c}^{c_{1}^{\star}} H(s) \int_{\Omega(s)} Q k_{c}(s, \omega) \mathrm{d} G(\omega) \mathrm{d} s .
\end{aligned}
$$


The latter expression corresponds to the utility type $c$ obtains in the optimal mechanism (see Lemma 1), which completes the proof.

\section{A.3. Proof of Proposition 3.}

Proof. We first verify the given equilibrium. It is optimal for the winning supplier to accept any offer that exceeds his second-period costs. Next, consider the buyer's strategy in period two. Assume the suppliers follow the proposed equilibrium strategy, the auction ended at price $p$, and state $\omega$ realized. Following Baye's rule the buyer believes the winning supplier's first-period cost are distributed according to the distribution function $F^{2}(c)=F(c) / F(p)$ on the interval $[\underline{c}, p]$ (i.e., the belief is a right-truncation of the prior). The buyer's optimal offer is a posted price (see e.g., Riley and Zeckhauser (1983)) and the solution to

$$
\max _{c \in[c, p]} Q(R-k(c, \omega)) \frac{F(c)}{F(p)} .
$$

By the definition of $c_{2}^{\star}(\omega)$ and strict concavity of the above objective we have that the buyer optimally offers $\min \left\{k\left(c_{2}^{\star}(\omega), \omega\right), k(p, \omega)\right\}$. It remains to confirm the optimality of the suppliers' strategy in period one. Following the proposed equilibrium strategy yields non-negative expected profit: if the supplier wins the first-period payment exceeds his cost, and in the second period, he only accepts profitable offers. Consequently, exiting the auction at an earlier point is not profitable as it leads to zero profit. If a supplier wins the auction at price $p<c$, he will not accept any offer the buyer makes in period two. This is because the buyer's offer is below $k(p, \omega)$ and we have that $k(p, \omega)<k(c, \omega)$ by assumption. Hence, if a supplier stays in the auction when the price drops below his $\operatorname{cost} c$, his profit will be non-positive. Either he wins at price $p<c$ and receives $p-c<0$, or he looses regardless.

Finally, we confirm that the buyer surplus equals the maximal surplus derived in Proposition 1. First, note that the allocation implemented in the described equilibrium of the English auction corresponds to the optimal allocation identified in Proposition 1. Second, the supplier's expected profit is

$$
\begin{aligned}
U(c)= & H\left(c_{1}^{\star}\right)\left(c_{1}^{\star}-c+\int_{\Omega} Q \max \left\{0, \min \left\{k\left(c_{1}^{\star}, \omega\right), k\left(c_{2}^{\star}(\omega), \omega\right)\right\}-k(c, \omega)\right\} \mathrm{d} G(\omega)\right) \\
& +\int_{c}^{c_{1}^{\star}}\left(s-c+\int_{\Omega} Q \max \left\{0, \min \left\{k(s, \omega), k\left(c_{2}^{\star}(\omega), \omega\right)\right\}-k(c, \omega)\right\} \mathrm{d} G(\omega)\right) \mathrm{d} H(s)
\end{aligned}
$$

Defining

$$
\Psi(s):=\int_{\Omega} Q \max \left\{0, \min \left\{k(s, \omega), k\left(c_{2}^{\star}(\omega), \omega\right)\right\}-k(c, \omega)\right\} \mathrm{d} G(\omega)
$$


and using similar arguments as in the proof of Lemma 2 we have that $\Psi(c)=\Psi(\underline{c})+\int_{\underline{c}}^{c}-\phi(s) \mathrm{d} s$. Using integration by parts we conclude that

$$
U(c)=\int_{c}^{c_{1}^{\star}} H(s) \mathrm{d} s+\int_{c}^{c_{1}^{\star}} H(s) \int_{\Omega(s)} Q k_{c}(s, \omega) \mathrm{d} G(\omega) \mathrm{d} s,
$$

and thus the buyer surplus in the English auction coincides with the maximal buyer surplus. 
Download ZEW Discussion Papers from our ftp server:

http://ftp.zew.de/pub/zew-docs/dp/

or see:

https://www.ssrn.com/link/ZEW-Ctr-Euro-Econ-Research.html

https://ideas.repec.org/s/zbw/zewdip.html

$$
\text { // }
$$

IMPRINT

ZEW - Leibniz-Zentrum für Europäische Wirtschaftsforschung GmbH Mannheim

ZEW - Leibniz Centre for European

Economic Research

L 7,1 68161 Mannheim · Germany

Phone +49621 1235-01

info@zew.de·zew.de

Discussion Papers are intended to make results of ZEW research promptly available to other economists in order to encourage discussion and suggestions for revisions. The authors are solely responsible for the contents which do not necessarily represent the opinion of the ZEW. 